\title{
CULTIVARES DE FEIJOEIRO IRRIGADO EM FUNÇÃO DE DOSES DE NITROGÊNIO EM COBERTURA
}

\author{
SOUZA, Stefany Silva de ${ }^{1}$ \\ CAMPOS, Talita Melo ${ }^{2}$ \\ SANTANA, Márcio José de ${ }^{2}$ \\ LEMOS, Leandro Borges ${ }^{3}$ \\ ALMEIDA, Fernando da Silva ${ }^{2}$
}

Recebido em: 2017.12.19

Aprovado em: 2019.03.29

ISSUE DOI: $10.3738 / 1982.2278 .2914$

\begin{abstract}
RESUMO: Adubação eficiente e manejo adequado da irrigação são técnicas essenciais para que a cultura do feijoeiro expresse seu potencial produtivo com sustentabilidade. Sendo assim, são necessárias informações acerca da adubação nitrogenada para as principais cultivares de feijoeiro utilizadas, sob irrigação. Este experimento foi conduzido com o objetivo de avaliar cultivares de feijoeiro comum irrigado, submetidas a doses de nitrogênio. Os tratamentos constaram de quatro doses de nitrogênio (50 kg ha ${ }^{-1}, 100 \mathrm{~kg} \mathrm{ha}^{-1}, 150 \mathrm{~kg} \mathrm{ha}^{-1}$ e $\left.200 \mathrm{~kg} \mathrm{ha}^{-1}\right)$ e seis cultivares de feijoeiro comum irrigadas (Pérola, BRSMG Madrepérola, BRSMG União, BRSMG Majestoso, IAC Alvorada e Ouro Vermelho). O delineamento foi em blocos casualizados, em esquema fatorial de $6 \times 4$ e quatro repetições. Foram avaliadas: número de vagens por planta, número de grãos por planta, número de grãos por vagem, produtividade de grãos, eficiência do uso da água e eficiência do uso do nitrogênio. Foram obtidas a evapotranspiração de referência e do feijoeiro. Dentre os resultados pode-se constatar que doses de nitrogênio promoveram aumento linear na produtividade de todas as cultivares avaliadas. A maior produtividade foi verificada com a cultivar Pérola adicionando-se $200 \mathrm{~kg} \mathrm{ha}^{-1} \mathrm{de} \mathrm{N}$, sendo de $3.550 \mathrm{~kg} \mathrm{ha}^{-1}$.
\end{abstract}

Palavras-chave: Manejo de adubação. Evapotranspiração. Phaseolus vulgaris L.

\section{BEAN CULTIVARS IRRIGATED CONCERNING DOSES OF NITROGEN TOPDRESSING}

SUMMARY: Efficient fertilization and proper management of irrigation are essential techniques for the common bean crop to express its productive potential with sustainability. Therefore, information about nitrogen fertilization is required for the main common bean cultivars used with irrigation. This experiment was conducted with the objective of to evaluate irrigated common bean cultivars, submitted to nitrogen doses. The design was in randomized blocks, in a 6x4 factorial and four replications. The treatments consisted of four nitrogen doses $\left(50 \mathrm{~kg} \mathrm{ha}^{-1}, 100 \mathrm{~kg} \mathrm{ha}{ }^{-1}, 150 \mathrm{~kg}\right.$ $\mathrm{ha}^{-1}$ and $200 \mathrm{~kg} \mathrm{ha}^{-1}$ ) and six irrigated common bean cultivars (Pérola, BRSMG Madrepérola, BRSMG União, BRSMG Majestoso, IAC Alvorada e Ouro Vermelho). The following were evaluated: number of pods per plant, number of grains per plant, number of grains per pod, grain yield, water use efficiency and nitrogen use efficiency. The reference evapotranspiration and the evapotranspiration common bean were obtained. Among the results it can be verified that nitrogen doses promoted a linear increase in productivity of all cultivars evaluated. The highest productivity was verified with a Pérola cultivar adding $200 \mathrm{~kg} \mathrm{ha}^{-1}$ of $\mathrm{N}$, being $3,550 \mathrm{~kg} \mathrm{ha}^{-1}$.

Keywords: Fertilization management. Evapotranspiration. Phaseolus vulgaris L.

\section{INTRODUÇÃO}

A sustentabilidade tem sido foco da agricultura mundial, buscando-se aliar a produção de

\footnotetext{
${ }^{1}$ Universidade Estadual Paulista "Júlio de Mesquita Filho", Faculdade de Ciências Agrárias e Veterinárias, campus Jaboticabal-SP - Engenheira Agrônoma pelo IFTM. Mestre e doutoranda em Agronomia (Produção Vegetal) na UNESP/FCAV.

${ }^{2}$ Instituto Federal do Triângulo Mineiro, campus Uberaba-MG

${ }^{3}$ Universidade Estadual Paulista "Júlio de Mesquita Filho", Faculdade de Ciências Agrárias e Veterinárias, campus Jaboticabal-SP
} 
alimentos ao uso consciente de recursos naturais, como a água, e de fertilizantes. Assim, na cultura do feijoeiro, a utilização de cultivares produtivas e adaptadas ao local de cultivo (FARINELLI; LEMOS, 2010) somada ao manejo adequado da irrigação e da adubação nitrogenada, destacam-se como técnicas que possibilitam elevadas produtividades de maneira sustentável (PACHECO et al., 2012).

O emprego da irrigação proporciona melhores condições para que as cultivares expressem o potencial produtivo. Devido a isto, o adequado fornecimento de nitrogênio pela adubação é primordial para sanar a necessidade em decorrência da elevação na atividade fotossintética, crescimento vegetativo e, consequentemente, produtividade da cultura (BISCARO et al., 2011; PACHECO et al., 2012).

Na cultura do feijoeiro, o nitrogênio é o nutriente mais absorvido e extraído, sendo que a adição por meio de adubação influência significativa a produtividade de grãos (VALDERRAMA et al. 2009). Porém, em virtude do alto custo dos fertilizantes nitrogenados e das perdas desse nutriente no solo, que contribuem para a poluição ambiental, torna-se de grande interesse a busca de técnicas que possam maximizar sua eficiência (SILVA et al. 2006).

Para Teixeira et al. (2008) a cultura do feijoeiro tem sido cada vez mais responsiva à aplicação de nitrogênio, o que está relacionado ao aumento da produtividade propiciado pela seleção de novas cultivares e técnicas de cultivo. Binotti et al. (2007) observaram que a adubação nitrogenada proporcionou aumento de $62 \%$ na média de produtividade de grãos em três cultivos, quando comparado com o tratamento sem aplicação do nutriente, para as cultivares de feijoeiro irrigado IAC Carioca Eté, Pérola e IAC Carioca. Lopes et al. (2014) evidenciaram que a máxima produtividade de grãos por planta da cultivar foi quando se aplicou a dose de nitrogênio estimada em $87,7 \mathrm{~kg} \mathrm{ha}^{-1}$ na cultivar Pérola.

Diante do exposto, objetivou-se com este trabalho determinar componentes de produção e variáveis do manejo de irrigação em relação a cultivares de feijoeiro irrigado submetidas a doses de nitrogênio.

\section{MATERIAL E MÉTODO}

O trabalho foi conduzido no município de Uberaba, MG, situado a $19^{\circ} 39^{\prime} 19^{\prime}$ ' S e $47^{\circ} 57^{\prime} 27^{\prime}$ ' W. O solo da área experimental é de topografia plana, do tipo Latossolo vermelho distroférrico e textura franco arenosa, com 81, 6 e 13\% de areia, silte e argila, respectivamente.

A análise dos atributos químicos do solo, na profundidade de $0-20 \mathrm{~cm}$, resultou em: $6,1 \mathrm{de} \mathrm{pH}$ (água); 1,6 dag kg${ }^{-1}$ de $\mathrm{MO} ; 65,6 \mathrm{mg} \mathrm{dm}^{-3} \mathrm{de} \mathrm{P} ; 48 \mathrm{mg} \mathrm{dm}^{-3} \mathrm{de} \mathrm{K}+; 1,9 \mathrm{cmolc} \mathrm{dm}^{-3} \mathrm{de} \mathrm{Ca}^{2+} ; 0,5 \mathrm{cmolc} \mathrm{dm}^{-3}$

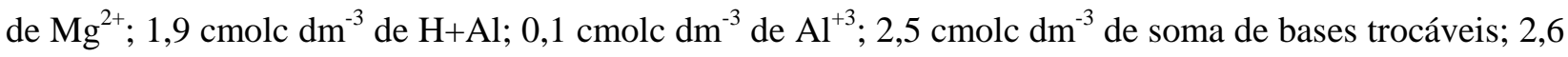
e 4,4 cmolc $\mathrm{dm}^{-3}$ de CTC efetiva e potencial, respectivamente, $57 \%$ de saturação por bases e 3,8\% de saturação por alumínio.

A densidade média do solo para as camadas de 0-20 e 20-40 $\mathrm{cm}$, obtida pelo método do cilindro de Uhland, forneceu valores de $1,21 \mathrm{e} 1,28 \mathrm{~g} \mathrm{~cm}^{-1}$, respectivamente. A umidade correspondente a capacidade de campo é de $0,22 \mathrm{~cm}^{3} \mathrm{~cm}^{-3}$ (tensão de água no solo média de $10 \mathrm{kPa}$ na camada de $0-20 \mathrm{~cm}$ ).

As cultivares implantadas foram Pérola, BRSMG Madrepérola, BRSMG União, BRSMG Majestoso, IAC Alvorada e Ouro Vermelho. A semeadura foi realizada no dia 20 de julho de 2011 e a colheita no dia 22 de outubro de 2011. Foi realizada uma subsolagem, uma aração e uma gradagem no solo da área experimental. A semeadura foi realizada à profundidade de, aproximadamente, $3 \mathrm{~cm}$ acima e ao lado do fertilizante de plantio, com 15 sementes por metro, permitindo 12 - 13 plantas por metro de sulco após emergência (ARF et al. 2004, MEIRA et al. 2005, SANTANA 2007).

A adubação de plantio foi realizada com 1,0 kg ha ${ }^{-1}$ de boro, 2,0 $\mathrm{kg} \mathrm{ha}^{-1}$ de zinco, $70 \mathrm{~kg} \mathrm{ha}^{-1} \mathrm{de}$ fósforo, $10 \mathrm{~kg} \mathrm{ha}^{-1}$ de potássio e $20 \mathrm{~kg} \mathrm{ha}^{-1}$ de nitrogênio. As doses totais de nutrientes NPK seguiram 
recomendação de Chagas et al. (1999) para o nível tecnológico $\mathrm{NT}_{4}$. As adubações de cobertura foram realizadas aos 20 dias após emergência, adicionando $20 \mathrm{~kg} \mathrm{ha}^{-1}$ de potássio e os diferentes tratamentos de nitrogênio (40\% da dose de cobertura), e aos 35 dias após emergência, com o restante do nitrogênio.

Antes da semeadura, foi realizado o tratamento das sementes com fungicida à base de fludioxonil $\left(2 \mathrm{~mL} \mathrm{~kg}^{-1}\right)$ e inseticida à base de tiametoxam $\left(2,5 \mathrm{~mL} \mathrm{~kg}^{-1}\right)$. O controle fitossanitário foi preventivamente realizado aos 20, 40 e 60 dias após emergência, buscando o controle das principais doenças e pragas na região: antracnose (Colletotrichum lindemuthianum), mancha-angular (Phaeoisariopsis griseola), mosca branca (Bemisia tabaci), vaquinha (Diabrotica speciosa) e lagarta da vagem (Etiella zinckenella). Os produtos aplicados foram o fungicida azoxystrobin e os inseticidas imidacloprido e clorpirifós.

$\mathrm{O}$ experimento foi conduzido em blocos casualizados (DBC) com quatro repetições, sendo empregado um esquema fatorial $6 \times 4$, constituído por seis cultivares e quatro doses de nitrogênio $(50 \mathrm{~kg}$ $\mathrm{ha}^{-1}, 100 \mathrm{~kg} \mathrm{ha}^{-1}, 150 \mathrm{~kg} \mathrm{ha}^{-1}$ e $200 \mathrm{~kg} \mathrm{ha}^{-1}$ ) aplicadas em cobertura. Cada parcela experimental foi constituída de cinco linhas de plantio com cinco metros de comprimento. As plantas localizadas ao centro da área foram consideradas plantas úteis para coleta dos dados (área de $2 \mathrm{~m}^{2}$ ).

Houve uma precipitação pluvial total durante a condução experimental de $148 \mathrm{~mm}$, sendo que as chuvas foram concentradas no mês de outubro de 2011. As irrigações foram efetuadas por meio de pivô central e o manejo conforme equações 1,2 e 3. As lâminas de irrigação foram as mesmas durante o ciclo para todas as cultivares. A evapotranspiração da cultura foi obtida por meio de tanque Classe A e, para auxílio do controle da umidade do solo em cada parcela de cada cultivar, foram instalados tensiômetros (à $10 \mathrm{~cm}$ de profundidade). Foram utilizados turnos de rega de 2 (dois) dias para reposição de água no solo.

$$
L B=\frac{E T c}{E a}
$$

em que:

Ea - eficiência de aplicação do sistema de irrigação $(0,9)$;

ETc - evapotranspiração da cultura (acumulado de dois dias, mm).

$$
\mathrm{ETc}=\mathrm{ETo} . \mathrm{Kc} . \mathrm{Ks}
$$

em que:

ETo - evapotranspiração de referência (acumulado de dois dias, mm);

Kc - coeficientes da cultura (conforme Santana et al. 2008);

Ks - coeficiente de déficit de água no solo.

$$
\mathrm{ETo}=\mathrm{Kt} . \mathrm{EV}
$$

em que:

$\mathrm{Kt}$ - coeficiente do tanque classe A;

EV - evaporação do tanque classe A ( $\mathrm{mm})$.

Foi instalada próximo a área experimental (400 m) uma estação meteorológica automática, com sensores de velocidade do vento, precipitação pluvial, umidade relativa do ar e temperatura.

Por ocasião da colheita, foram coletadas em 10 plantas da área útil: número de grãos por planta, número de grãos por vagem e número de vagens. A colheita foi realizada manualmente, os grãos foram pesados e tiveram seu grau de umidade determinado em medidor padrão, para correção do peso para umidade de 13\% (base úmida), conforme Equação 4 (Arf et al. 2004, Santana 2007). O peso dos grãos foi expresso em kg ha-1. 


$$
P=\frac{P c .(100-U o)}{(100-U i)}
$$

em que:

$\mathrm{P}$ - peso corrigido $\left(\mathrm{kg} \mathrm{ha}^{-1}\right)$;

Pc - peso de campo $\left(\mathrm{kg} \mathrm{ha}^{-1}\right)$;

Uo - umidade medida após colheita $(\%)$;

Ui - umidade de correção (13\%).

Os dados de produtividade, número de grãos por planta, número de grãos por vagem e número de vagens por planta foram submetidos à análise de variância, sendo os efeitos dos tratamentos estudados por meio de análise de regressão ou do teste de média Scott-Knott, conforme o caso. A ferramenta utilizada para as análises foi o software Sisvar for Windows, versão 4.3. Obteve-se a eficiência do uso da água (Equação 5) e do nitrogênio (Equação 6).

$$
E U A=\frac{P R O D}{L A M}
$$

em que:

EUA- eficiência do uso da água para cada cultivar $\left(\mathrm{kg} \mathrm{mm}^{-1} \mathrm{ha}^{-1}\right)$;

PROD. - produtividade de cada cultivar $\left(\mathrm{kg} \mathrm{ha}^{-1}\right)$;

LAM.- lâmina de irrigação aplicada durante o ciclo (mm).

$$
E U N=\frac{P R O D}{D N}
$$

em que:

EUN- eficiência do uso da água para cada cultivar $\left(\mathrm{kg} \mathrm{kg}^{-1}\right)$;

PROD. - produtividade de cada cultivar $\left(\mathrm{kg} \mathrm{ha}^{-1}\right)$;

DN.- dose de nitrogênio aplicada $\left(\mathrm{kg} \mathrm{ha}^{-1}\right)$.

\section{RESULTADO E DISCUSSÃO}

Entre as cultivares de feijoeiro, a maior tensão de água foi verificada para a cultivar BRSMG União e a menor para a cultivar BRSMG Majestoso (Tabela 3). Assim, como a lâmina de água irrigada $(527,81 \mathrm{~mm})$ foi a mesma para todas as cultivares e a tensão diferenciou, ocorreu então diferença de consumo hídrico entre os genótipos, sendo que as cultivares BRSMG União e BRSMG Majestoso apresentaram, respectivamente, maior e menor consumo. Uma forma fundamental de programar a irrigação é através do monitoramento da tensão da água do solo, que é a força necessária para que as raízes das plantas extraiam a água do solo (SHOCK; WANG, 2011). A tensão ótima para realizar a irrigação do feijoeiro varia desde 25 (STONE; MOREIRA, 1986) até $70 \mathrm{kPa}$ (SAAD et al. 1992). Silveira e Stone (2004) afirmam que a faixa ótima de tensão para a irrigação desta cultura é de 30 a $40 \mathrm{kPa}$. 
Tabela 3. Tensão média de água no solo, evapotranspiração e lâmina irrigada.

\begin{tabular}{|c|c|c|c|c|c|c|}
\hline \multirow{2}{*}{ Cultivares } & \multirow{2}{*}{$\begin{array}{l}\text { Tensão de água } \\
\text { no solo média } \\
\text { (kPa) }\end{array}$} & \multicolumn{2}{|c|}{$\begin{array}{l}\text { Evapotranspiração de } \\
\text { referência }\end{array}$} & \multicolumn{2}{|c|}{$\begin{array}{c}\text { Evapotranspiração } \\
\text { da cultura }\end{array}$} & \multirow{2}{*}{$\begin{array}{r}\begin{array}{r}\text { Lâmina } \\
\text { irrigada }\end{array} \\
(\mathrm{mm})\end{array}$} \\
\hline & & $\begin{array}{l}\text { Total } \\
(\mathbf{m m})\end{array}$ & $\begin{array}{c}\text { Média } \\
\left(\mathrm{mm} \mathrm{dia}^{-1}\right)\end{array}$ & $\begin{array}{l}\text { Total } \\
(\mathbf{m m})\end{array}$ & $\begin{array}{c}\text { Média } \\
(\mathbf{m m} \\
\left.\text { dia }^{-1}\right)\end{array}$ & \\
\hline $\begin{array}{l}\text { BRSMG } \\
\text { Madrepérola } \\
\text { Pérola } \\
\text { IAC Alvorada } \\
\text { BRSMG Majestoso } \\
\text { BRSMG União } \\
\text { Ouro Vermelho }\end{array}$ & $\begin{array}{l}21,03 \\
16,17 \\
14,54 \\
27,42 \\
21,16\end{array}$ & 478,04 & 5,08 & 400,33 & 4,26 & 527,81 \\
\hline
\end{tabular}

Além disso, através dos valores diários de tensão de água (Figura 1), constatou-se que os maiores índices foram obtidos entre 60 e 75 dias após semeadura (DAS). Neste período as cultivares estavam na fase de enchimento de grãos havendo maior consumo de água. Dessa maneira, foram verificados também neste período, maiores valores diários de evapotranspiração de cultura (Figura 2).

Figura 1. Tensão média de água no solo para as cultivares implantadas

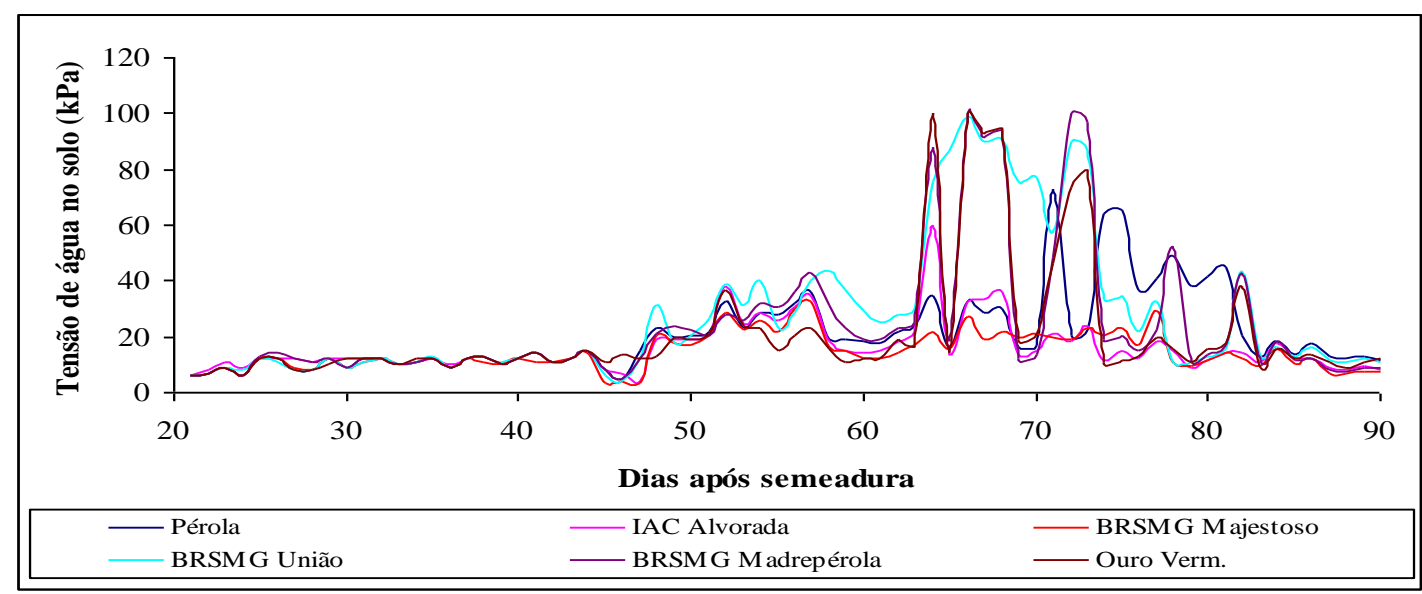

Figura 2. Evapotranspiração da cultura e de referência durante o ciclo.

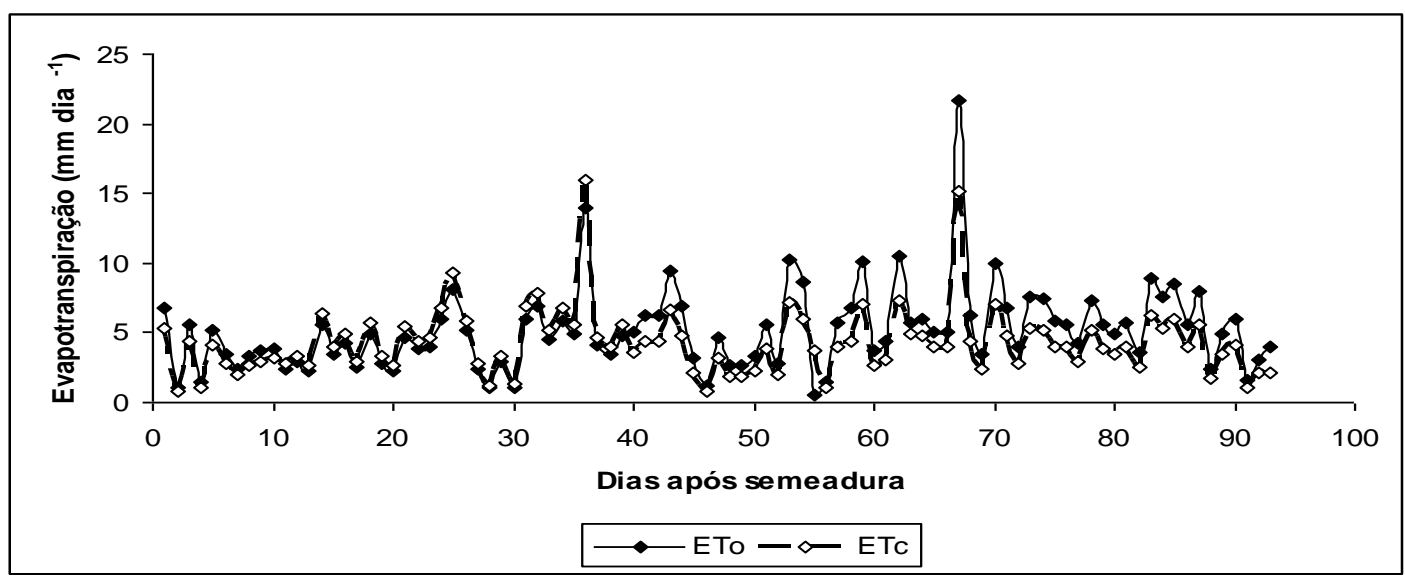


As médias de ETo e ETc foram 5,08 $\mathrm{mm}$ e 4,26 mm, respectivamente (Tabela 3). Pavani et al. (2008) encontraram valores de evapotranspiração real média no ciclo da cultivar IAC Carioca de 3,97 mm e 4,43 mm quando o manejo da irrigação foi efetuado por tensiometria (plantio convencional e direto, respectivamente) e de 4,82 $\mathrm{mm}$ e 4,66 mm quando o manejo da irrigação foi efetuado por tanque Classe A (plantio convencional e direto, respectivamente).

Quanto ao número de grãos por planta, de vagens por planta e de grãos por vagem houve diferença estatística apenas entre as cultivares implantadas (Tabela 4). Assim, enquanto os maiores valores para número de grãos e de vagens por planta foram verificados para a cultivar Pérola, a variável número de grãos por vagens foi maior nas cultivares Pérola, BRSMG Madrepérola e Ouro Vermelho. Concordando com este estudo, Lopes et al. (2011) não verificaram influência de doses de $\mathrm{N}\left(0\right.$ a $\left.150 \mathrm{~kg} \mathrm{ha}^{-1} \mathrm{de} \mathrm{N}\right)$ para número de vagens por planta e de grãos por vagem para o feijoeiro cultivar pérola. Binotti et al. (2007) evidenciaram que o número de grãos por vagem esteja mais relacionado com a cultivar utilizada, sofrendo pouca influência das práticas culturais utilizadas na cultura do feijoeiro como a irrigação e adubação, sendo estes valores normalmente entre 4 a 5 grãos por vagem. Salgado et al. (2011) quando trabalharam com 14 cultivares no estado do Tocantins observaram que em 10 genótipos, o número de vagens por planta foi inferior a 20 .

Tabela 4. Média do número de grãos por planta (NGP) e número de vagens por planta (NVP) e número de grãos por vagem (NGV) em função da cultivares de feijoeiro.

\begin{tabular}{lccc}
\hline Cultivares & NGP & NVP & NGV \\
\hline Pérola & $77,11 \mathrm{a}^{\mathbf{1}}$ & $19,68 \mathrm{a}$ & $4,04 \mathrm{a}$ \\
BRSMG & $54,60 \mathrm{~b}$ & $12,39 \mathrm{~b}$ & $4,56 \mathrm{a}$ \\
Madrepérola & & & \\
BRSMG Majestoso & $51,33 \mathrm{~b}$ & $13,83 \mathrm{~b}$ & $3,91 \mathrm{~b}$ \\
Ouro Vermelho & $49,35 \mathrm{~b}$ & $11,14 \mathrm{~b}$ & $4,16 \mathrm{a}$ \\
IAC Alvorada & $32,08 \mathrm{c}$ & $10,62 \mathrm{~b}$ & $3,45 \mathrm{~b}$ \\
BRSMG União & $18,37 \mathrm{c}$ & $6,77 \mathrm{~b}$ & $3,37 \mathrm{~b}$ \\
\hline
\end{tabular}

Para a produtividade de grãos, ocorreu interação entre os fatores estudados cultivares e doses de $\mathrm{N}$ em cobertura (Tabela 5). Quando foi aplicado no solo a maior dose de N (200 kg ha ${ }^{-1}$ ), verificou-se que a cultivar Pérola apresentou maior valor para esta variável. Além disso, esta cultivar foi a única que obteve maior produtividade de grãos em três das quatro doses testadas, destacando-se que na menor dose (50 $\mathrm{kg}$ $\mathrm{ha}^{-1}$ ), Pérola, BRSMG Madrepérola e IAC Alvorada, foram as cultivares que sobressaíram nesta variável. A Pérola é uma das cultivares mais cultivadas no Brasil (SORATTO et al., 2013), por ser referência em produtividade e qualidade de grãos (MELO et al., 2006).

Tabela 5. Produtividade do feijoeiro $\left(\mathrm{kg} \mathrm{ha}^{-1}\right)$ em cada dose de $\mathrm{N}$ aplicada em função das cultivares.

\begin{tabular}{lcccc}
\hline \multirow{2}{*}{ Cultivares } & \multicolumn{4}{c}{ Doses de N $\left(\mathbf{k g ~ h a}^{-1}\right)$} \\
\cline { 2 - 5 } & $\mathbf{5 0}$ & $\mathbf{1 0 0}$ & $\mathbf{1 5 0}$ & $\mathbf{2 0 0}$ \\
\hline BRSMG Madrepérola & $1.651,00 \mathrm{a}^{1}$ & $2.137,66 \mathrm{a}$ & $2.503,33 \mathrm{~b}$ & $2.548,00 \mathrm{c}$ \\
Pérola & $1.329,00 \mathrm{a}$ & $1.650,66 \mathrm{~b}$ & $3.261,00 \mathrm{a}$ & $3.550,00 \mathrm{a}$ \\
IAC Alvorada & $1.371,66 \mathrm{a}$ & $1.826,66 \mathrm{a}$ & $2.433,66 \mathrm{~b}$ & $2.660,33 \mathrm{c}$ \\
BRSMG Majestoso & $880,33 \mathrm{~b}$ & $1.355,66 \mathrm{~b}$ & $2.909,33 \mathrm{a}$ & $2.928,66 \mathrm{~b}$ \\
BRSMG União & $735,00 \mathrm{~b}$ & $1.375,33 \mathrm{~b}$ & $2.046,00 \mathrm{~b}$ & $2.301,00 \mathrm{c}$ \\
Ouro Vermelho & $642,66 \mathrm{~b}$ & $1.375,00 \mathrm{~b}$ & $2.044,00 \mathrm{~b}$ & $2.046,66 \mathrm{c}$ \\
\hline
\end{tabular}

${ }^{ }$As médias seguidas pela mesma letra na vertical não diferem entre si estatisticamente pelo teste de Scott-Knott.

Em função da aplicação de doses de N, ocorreu aumento linear da produtividade de grãos para 
todas as cultivares estudadas (Figuras 3 a 8). Salgado et al. (2012) avaliando o efeito do N em genótipos de feijão no estado do Tocantins, verificaram que sete dos doze genótipos avaliados responderam de forma positiva ao acréscimo do elemento, com produtividades médias variando entre 816 a $2.417 \mathrm{~kg} \mathrm{ha}^{-1}$ (cultivares BRS-Marfim e Princesa, respectivamente). Silva et al. (2006) testaram diferentes doses de N e Mo na cultivar Pérola e constataram que os tratamentos não influenciaram a produtividade de grãos. As doses testadas por estes autores foram entre 0 e $120 \mathrm{~kg} \mathrm{ha}^{-1} \mathrm{em}$ e as produtividades verificadas foram entre 2.028 e $2.047 \mathrm{~kg} \mathrm{ha}^{-1}$. Amaral et al. 2016 verificaram efeito de doses de $\mathrm{N}\left(0,40,80,120\right.$ e $\left.160 \mathrm{~kg} \mathrm{ha}^{-1}\right)$ em cobertura sobre a produtividade do feijoeiro, cultivar IPR Andorinha, sendo que a máxima produtividade de grãos $\left(2.565 \mathrm{~kg} \mathrm{ha}^{-1}\right)$ foi obtida com aplicação de $136 \mathrm{~kg} \mathrm{ha}^{-1}$ de N. Além disso, estes autores concluíram que esta variável foi maior quando o feijoeiro foi cultivado sobre palhada de Urochloa ruziziensis. Assim, a dose de $\mathrm{N}$ parece estar diretamente relacionada com a cultivar, local de cultivo e manejo cultural.

Figura 3. Produtividade média do feijoeiro em função das doses de $\mathrm{N}$ para a cultivar IAC Alvorada.

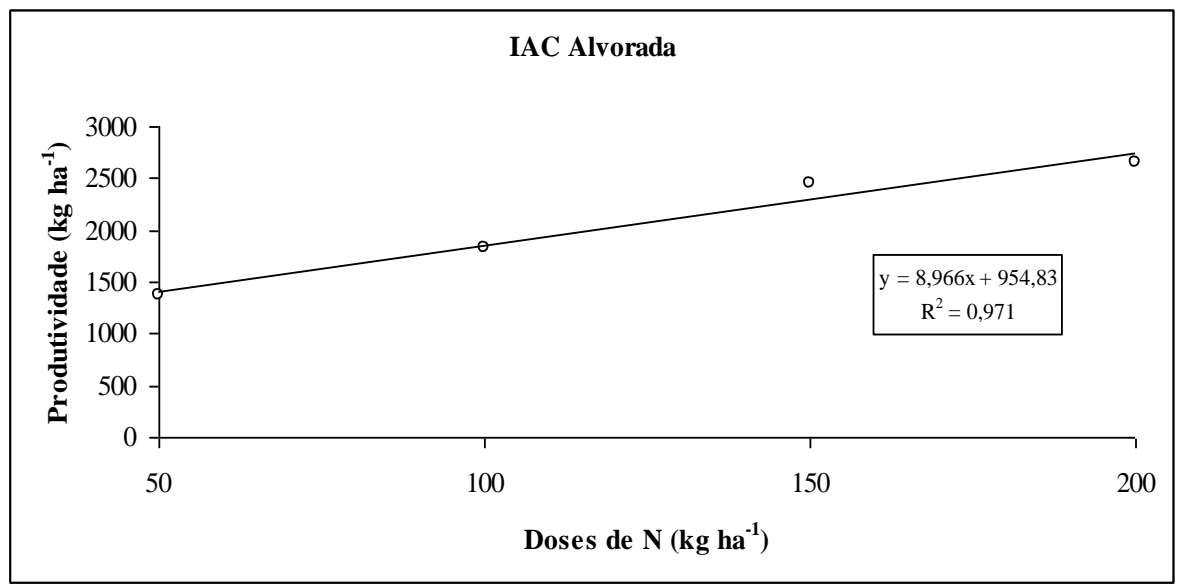

Figura 4. Produtividade média do feijoeiro em função das doses de N para a cultivar BRSMG Majestoso.

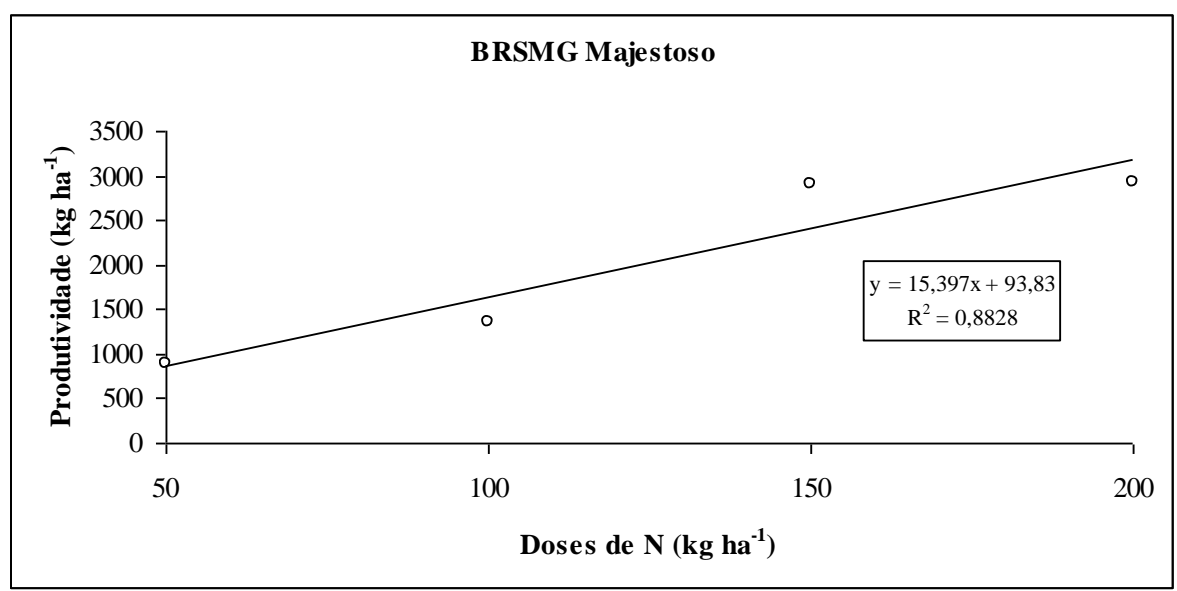


Figura 5. Produtividade média do feijoeiro em função das doses de $\mathrm{N}$ para a cultivar BRSMG Madrepérola.

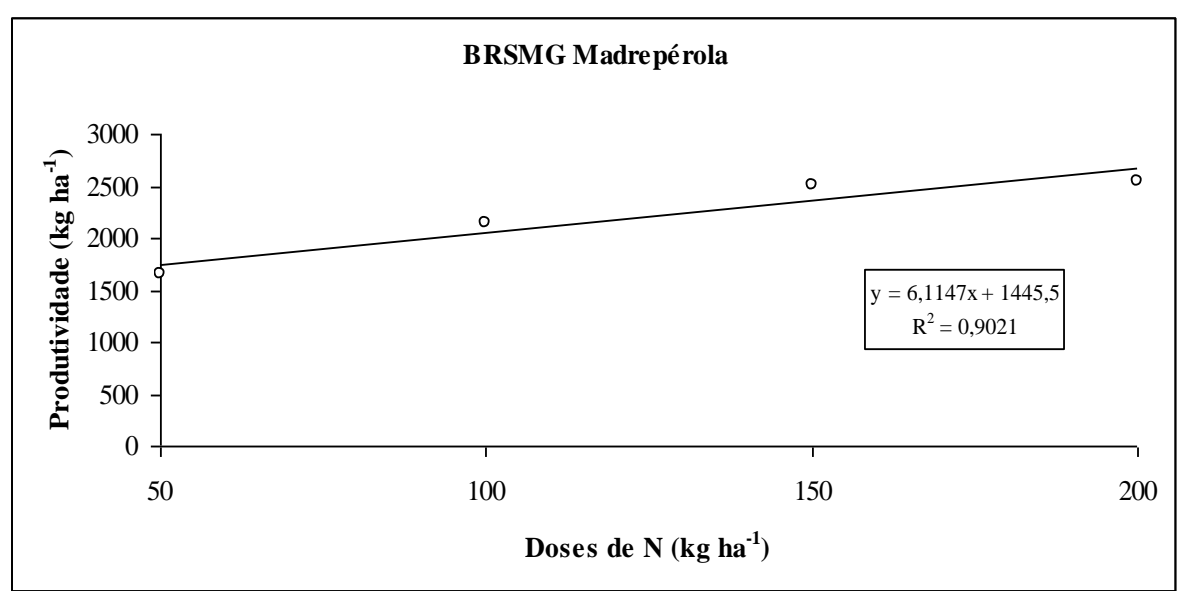

Figura 6. Produtividade média do feijoeiro em função das doses de N para a cultivar Ouro Vermelho.

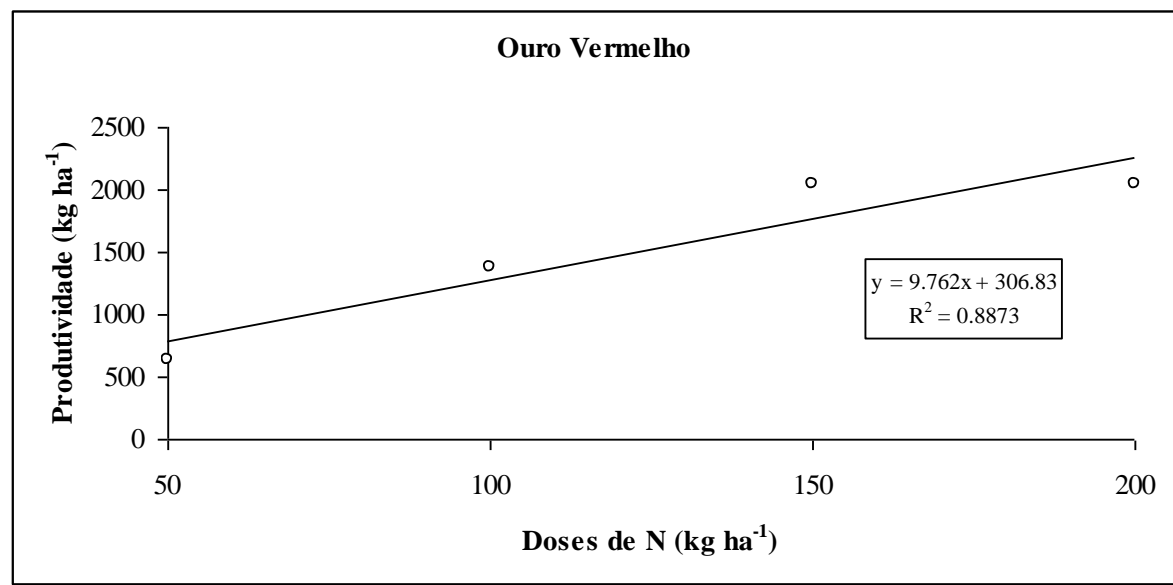

Figura 7. Produtividade média do feijoeiro em função das doses de $\mathrm{N}$ para a cultivar Pérola.

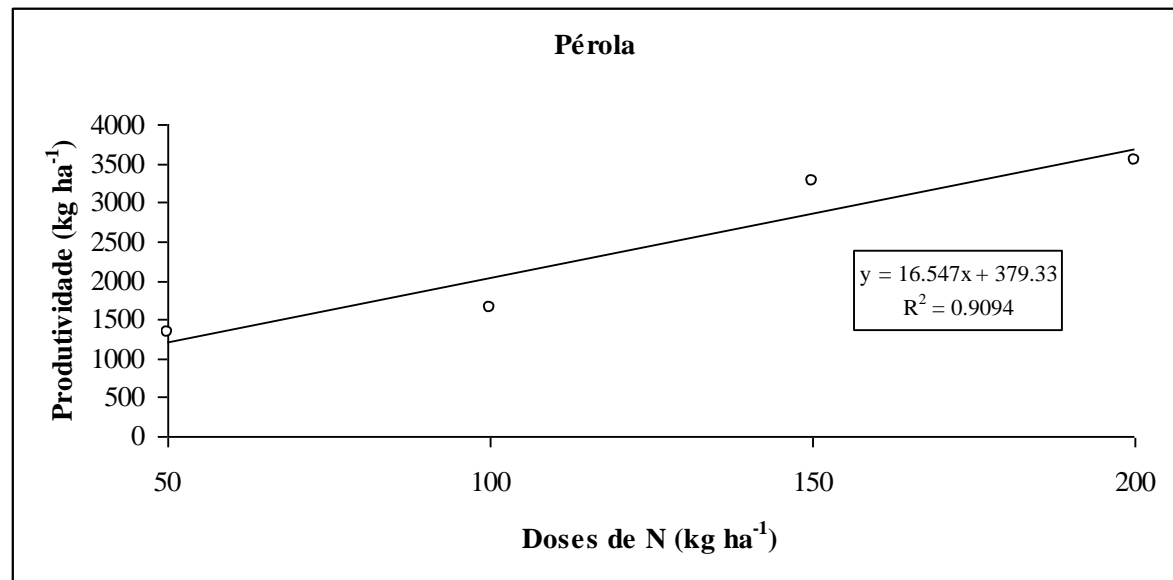


Figura 8. Produtividade média do feijoeiro em função das doses de N para a cultivar BRSMG União.

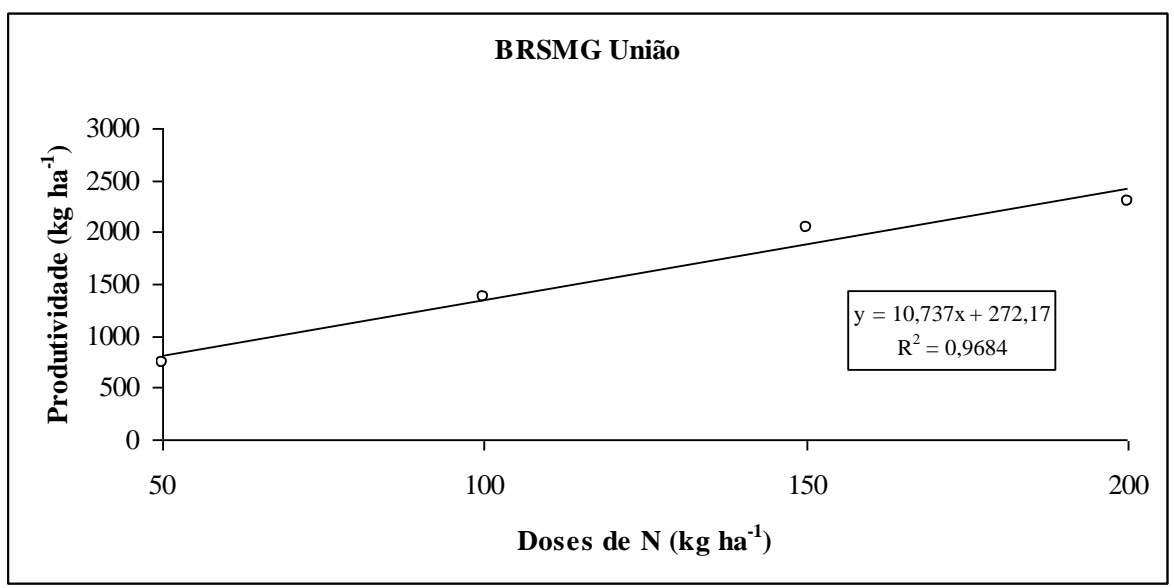

Com aumento da dose de $\mathrm{N}$ verificou-se aumento da eficiência do uso da água (EUA) conforme verificado na Figura 9. Santana et al. (2008) verificaram valores de eficiência do uso da água variando de 2,66 a $10 \mathrm{~kg} \mathrm{ha}^{-1} \mathrm{~mm}^{-1}$ em função das reposições de água no solo e épocas de suspensão da irrigação, sendo que maiores médias encontradas quando a irrigação foi efetuada com $40 \%$ da evapotranspiração da cultura. Para a cultura do feijoeiro, o valor da eficiência de uso da água, no caso da produção de grãos com umidade de $10 \%$, é da ordem de 0,3 a 0,6 $\mathrm{kg} \mathrm{m}^{-3}$ (DOORENBOS; KASSAM, 1979).

Figura 9. Eficiência do uso da água em função das doses de $\mathrm{N}$ aplicadas.

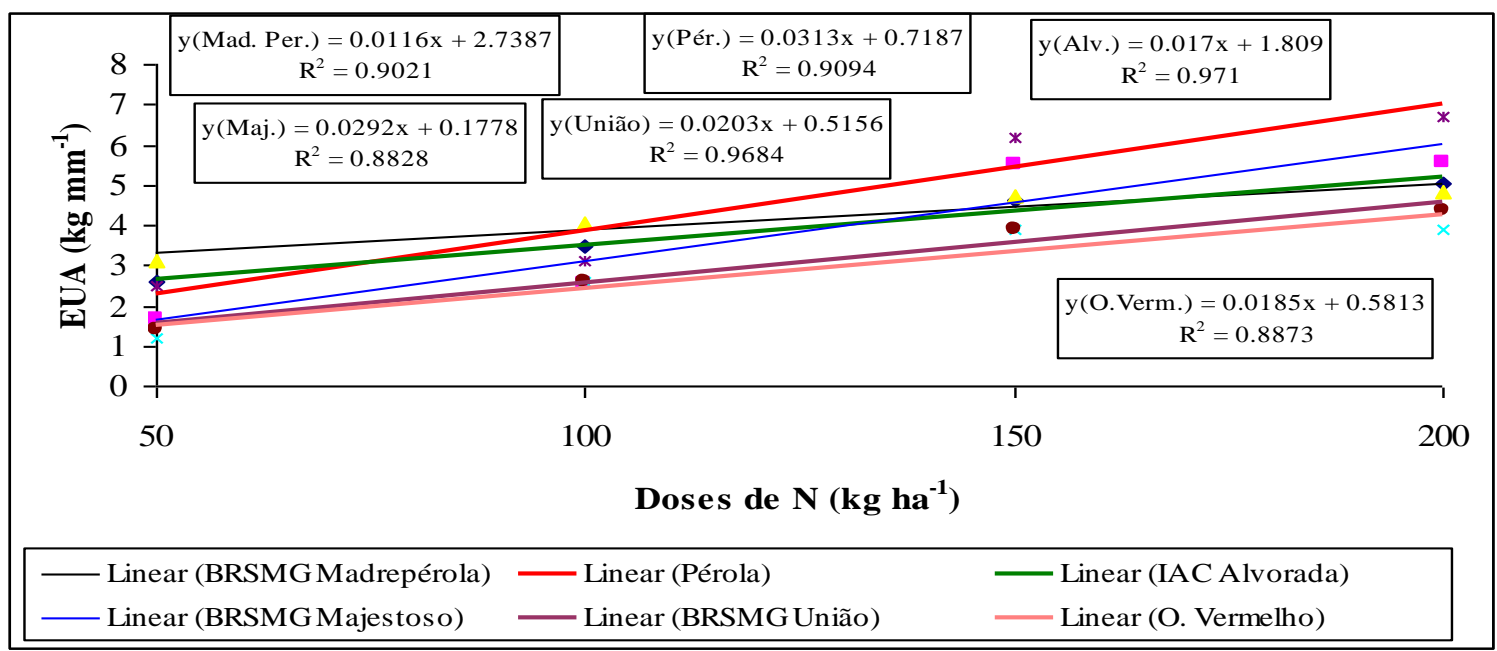

As menores eficiências do uso de nitrogênio (EUN) foram verificadas nas maiores doses aplicadas do nutriente (Figura 10). Para Sant'ana et al. (2011) a melhoria da eficiência do uso do N é desejável para aumentar a produtividade, reduzir os cultos de produção e manter a qualidade ambiental. Ainda segundo estes mesmos autores a EUN pelo feijoeiro variou com doses de $\mathrm{N}$ aplicadas e com o tipo de eficiência calculada, sendo que o aumento das doses de $\mathrm{N}$ testadas diminuiu a EUN. 
Figura 10. Eficiência do uso do nitrogênio.

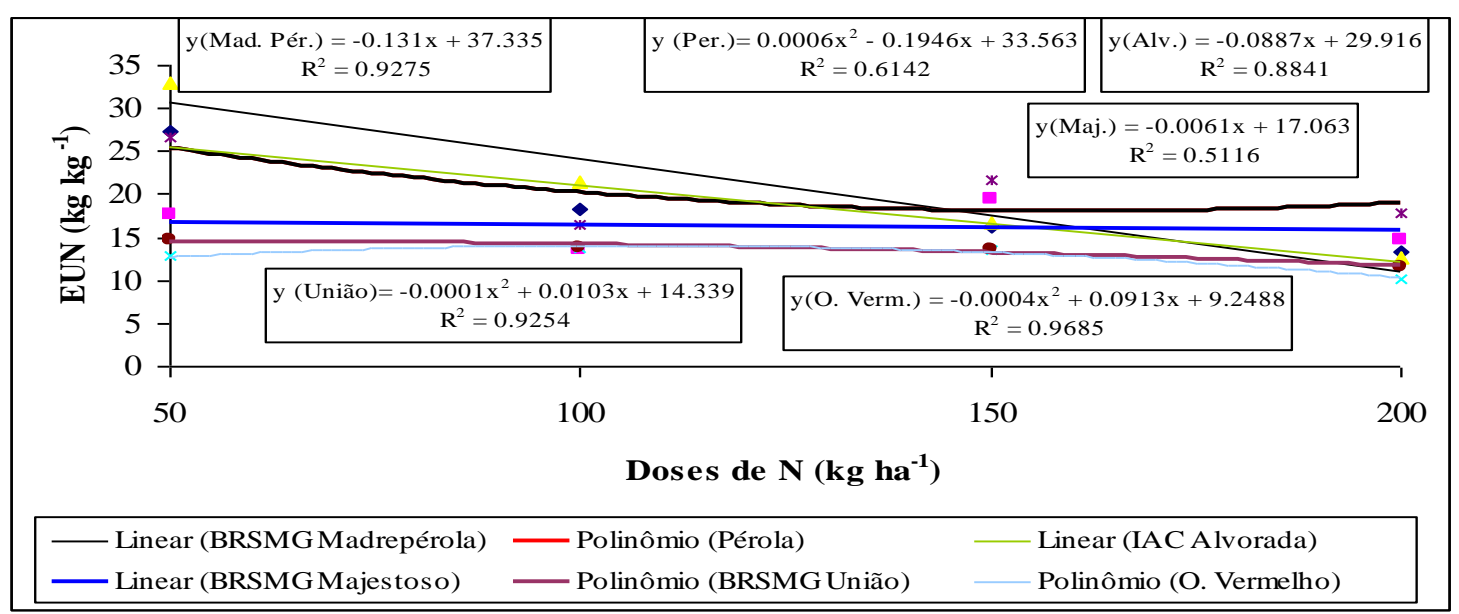

\section{CONCLUSÃO}

Pode-se concluir que doses de nitrogênio promoveram aumento linear na produtividade de todas as cultivares testadas. A maior produtividade foi verificada com a cultivar Pérola adicionando-se $200 \mathrm{~kg}$ $\mathrm{ha}^{-1}$ sendo de $3.550,00 \mathrm{~kg} \mathrm{ha}^{-1}$. Não houve interferência das doses de nitrogênio no número de grãos por planta, número de grãos por vagem e vagens por planta. Houve uma queda linear da eficiência do uso de nitrogênio com aumento da dose de $\mathrm{N}$ e da eficiência do uso da água com diminuição da dose de $\mathrm{N}$.

\section{REFERÊNCIAS}

AMARAL, C.B. do et al. Produtividade e qualidade do feijoeiro cultivado sobre palhadas de gramíneas e adubado com nitrogênio em plantio direto. Pesquisa Agropecuária Brasileira, v.51, n.9, p.1602-1609, 2016.

ARF, O. et al. Manejo do solo, água e nitrogênio no cultivo do feijão. Pesquisa Agropecuária Brasileira, v.39, n.2, p.131-138, 2004.

BINOTTI, F.F.S. et al. Manejo do solo e da adubação nitrogenada na cultura de feijão de inverno e irrigado. Bragantia, v.66, n.1, p. 121-129-624, 2007.

BISCARO, G. A. et al. Nitrogênio em cobertura e molibdênio via foliar no feijoeiro irrigado cultivado em solo de Cerrado. Acta Scientiarum Agronomy, v. 33, n. 4, p. 665-670, 2011.

CHAGAS, J. M. et al. Recomendação adubação para o feijão. In: RIBEIRO, A. C.; GUIMARÃES, P. T.; ALVAREZ, V. H. Recomendações para o uso de corretivos e fertilizantes em Minas Gerais. Comissão de fertilidade do solo do estado de Minas Gerais, 1999. p. 306-308.

DOORENBOS, J.; KASSAM, A. H. Yield response to water. Roma: FAO. 1979. 193 p. (Tecnical note, $33)$.

FARINELLI, R.; LEMOS, L.B. Características agronômicas de genótipos de feijoeiro cultivados nas épocas da seca e das águas. Bragantia, v.69, n.2, p.361-366, 2010.

LOPES, A. da S. Lâminas de irrigação e doses de nitrogênio em cobertura no feijoeiro. Engenharia na Agricultura, v.22, n.4, p.351-360, 2014. 
LOPES, A.S. et al. Manejo de irrigação e nitrogênio no feijoeiro comum cultivado em sistema de plantio direto. Ciência Agronômica, v.42, n.1, p.51-56, 2011.

MEIRA, F.A. et al. Doses e épocas de aplicação de nitrogênio no feijoeiro irrigado cultivado em plantio direto. Pesquisa Agropecuária Brasileira, v.40, n.4, p.383-388, 2005.

MELO, C.L.P. et al. Linhagens de feijão do cruzamento 'Ouro Negro' x 'Pérola' com características agronômicas favoráveis. Pesquisa Agropecuária Brasileira, v.41, n.11, p.1593-1598, 2006.

PACHECO, A. et al. Manejos de irrigação e nitrogênio na produção de feijoeiro sob plantio direto. Pesquisa Agropecuária Tropical, v.42, n.3, p.323-330, 2012.

PAVANI, L.C.; LOPES, A.S.; GALBEIRO, R.B. Manejo da irrigação na cultura do feijoeiro em sistemas plantio direto e convencional. Engenharia Agrícola, v.28, n.1, p.12-21, 2008.

SAAD, A. M.; DOURADO NETO, D.; JONG VAN LIER, Q. Controle de irrigação pelo método do tensiômetro na cultura do feijão sob pivô central. In: FANCELLI, A. L.; DOURADO NETO, D. Feijão irrigado. 3. ed. ESALQ, 1992. 177 p.

SALGADO, F.H.M. et al. Comportamento de genótipos de feijão, no período da entressafra, no sul do estado do Tocantins. Bioscience Journal, v.27, n.1, p.52-58, 2011.

SALGADO, F.H.M. et al. Efeito do nitrogênio em feijão cultivado em terras altas no sul do estado de Tocantins. Ambiência, v.8, n.1, p.125-136, 2012.

SANT'ANA, E.V.P.; SANTOS, A.B.; SILVEIRA, P.M. Eficiência do uso do nitrogênio em cobertura pelo feijoeiro irrigado. Revista Brasileira de Engenharia Agrícola e Ambiental, v.15, n.5, p.458-462, 2011.

SANTANA M.J. Resposta do feijoeiro comum a lâminas e épocas de suspensão da irrigação. 2007. 102 f. Tese (Doutorado em Engenharia Agrícola) - Universidade Federal de Lavras, Lavras.

SANTANA, M.J. et al. Coeficiente de cultura e análise do rendimento do feijoeiro sob regime de irrigação. Irriga, v.13, n.1, p.92-112, 2008.

SHOCK, C.C.; WANG, F. Soil water tension, a powerful measurement for productivity and stewardship. Hortscience, v.46, n.2, p.178-195, 2011.

SILVA, T.R.B.; LEMOS, L.B.; TAVARES, C.A. Produtividade e características tecnológica de grãos em feijoeiro adubado com nitrogênio e molibdênio. Pesquisa Agropecuária Brasileira, v.41, n.5, p.739-745, 2006.

SILVEIRA, P.M.; STONE, L.F. Irrigação. In: EMPRESA DE PESQUISA AGROECUÁRIA DE MINAS GERAIS. Informe agropecuário: feijão de alta produtividade. p. 74-82, 2004.

SORATTO, R.P. et al. Nutrient extraction and exportation by common bean cultivars under different fertilization levels: I - macronutrients. Revista Brasileira de Ciência do Solo, v.37, p.1027-1042, 2013.

STONE, L. F.; MOREIRA, J. A. A. Irrigação do feijoeiro. EMBRAPA/CNPAF, 1986. 31 p. (EMBRAPA/CNPAF. Circular Técnica, 20).

TEIXEIRA, C.M. et al. Produtividade e teores foliares de nutrientes do feijoeiro sob diferentes palhadas e doses de nitrogênio em semeadura direta. Acta Scientiarum Agronomy, v.30, n.1, p.123-130, 2008.

VALDERRAMA, M. et al. Fontes e doses de nitrogênio e fósforo em feijoeiro no sistema plantio direto. Pesquisa Agropecuária Brasileirav.39, n.3, p. 191-196, 2009. 